\title{
URGENSI PENGELOLAAN KAWASAN KARST GOA PINDUL, KECAMATAN KARANGMOJO, GUNUNGKIDUL
}

\author{
Slamet Suprayogi, Ahmad Cahyadi dan Romza Fauzan Agniy \\ Departemen Geografi Lingkungan, Fakultas Geografi, Universitas Gadjah Mada \\ Yogyakarta
}

\section{Intisari}

Goa Pindul adalah salah satu wisata andalan di Kabupaten Gunungkidul, Daerah Istimewa Yogyakarta. Konflik sosial yang terjadi akibat koordinasi dan peran pemerintah yang masih minim menyebabkan situasi pariwisata yang kurang kondusif dalam pengembangan wisata yang berkelanjutan. Selain itu, karakteristik unik kawasan karst yang dipengaruhi oleh perkembangan pelorongan akibat proses pelarutan dan sistem allogenik mengharuskan pengelolaan yang berwawasan bencana dengan membuat sistem pemantauan banjir, early warning system dan emergency response system untuk pengurangan risiko bencana yang mungkin terjadi di Kawasan Wisata Goa Pindul.

Kata Kunci: Goa Pindul, Pengelolaan, Wisata, Karst

\section{Pendahuluan}

Seiring dengan berakhirnya era Millenium Development Goals (MDGs), sekitar 154 kepala negara dan pemerintahan yang tergabung dalam Persatuan Bangsa-bangsa (PBB) secara resmi mengadopsi agenda 2030 untuk pembangunan berkelanjutan pada siding ke-70 Majelis Umum PBB di New York. Agenda yang disepakati ini kemudian lebih dikenal sebagai agenda Sustainable Development Goals (SDGs). Agenda ini terdiri dari 17 tujuan (Gambar 1).

Pariwisata sebagai salah satu sektor ekonomi yang dinamis tentunya memiliki peranan terhadap terlaksananya pembangunan berkelanjutan (Muta'ali, 2011; 2013). Berbagai pendekatan seperti ekowisata dan geowisata diklaim akan memberikan peningkatan ekonomi bagi kesejahteraan masyarakat dengan tetap menjaga kelestarian lingkungan. Oleh karena itu, tidak salah apabila dalam agenda SDGs, sektor pariwisata setidaknya menempati tiga tujuan dari total 17 tujuan yang hendak dicapai. 


\section{SUSTAINABLE G}
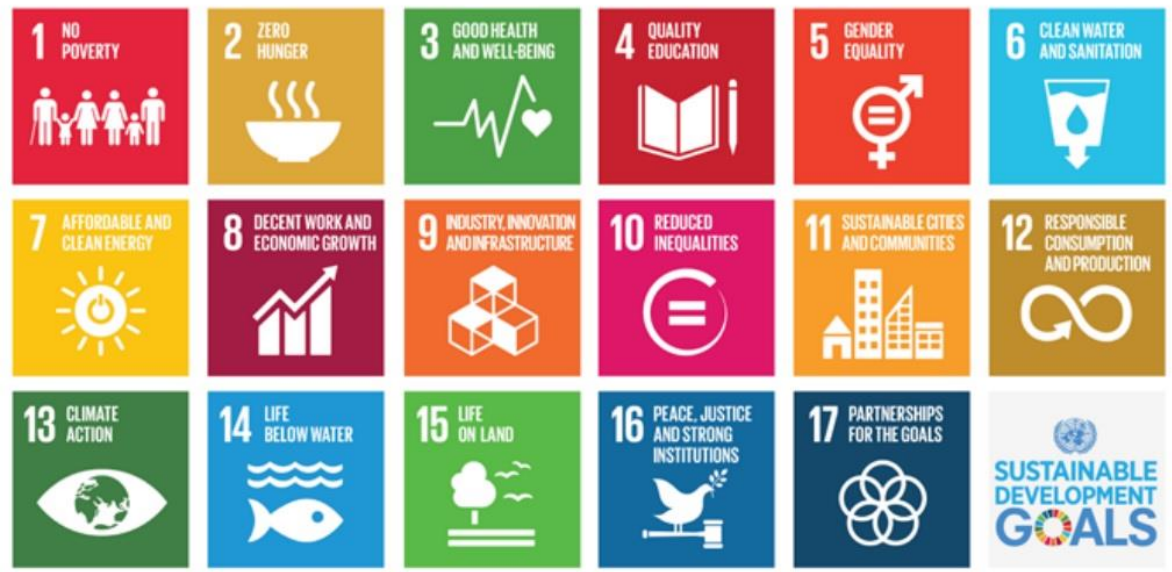

SUSTAINABLE DEVELOPMENT GOALS

Gambar 1. Tujuh Belas Tujuan dalam Agenda Sustainable Development Goals (SDGs) (UNWTO, 2016)

Tujuan ke-8 dalam SDGs fokus pada penyediaan lapangan kerja dan pertumbuhan ekonomi. Poin 8.9 dalam target SDGs mengharuskan dilakukannya penyusunan dan pelaksanaan kebijakan untuk mempromosikan pariwasata yang berkelanjutan yang menciptakan lapangan kerja, yang secara khusus harus ikut dalam mempromosikan budaya dan produk lokal dari wilayah yang dikembangkan.Keberadaan pariwisata akan berperan dalam penciptaan lapangan kerja dan tentunya pada akhirnya ikut dalam meningjkatkan pertumbuhan ekonomi suatu wilayah.

Tujuan ke-12 dalam SDGs fokkus pada usaha-usaha mencapai pola konsumsi dan produksi yang berkelanjutan. Salah satu poin pada tujuan ke12, yakni pada 12.b. disebutkan bahwa salah langkah yang akan harus dilakukan untuk mencapai tujuan ke-12 adalah mengembangkandan menerapkan alat/teknologi untuk pemantauan dampak pembangunan berkelanjutan, termasuk di dalamnya pemantauan dampak pariwisata berkelanjutan yang dijalankan.

Tujuan ke-14 dari SDGs mengamanatkan untuk melakukan penghematan dan pemanfaatan sumberdaya laut yang berkelanjutan dalam rangka mendukung pembangunan berkelanjutan. Termasuk di dalam tujuan ini adalah pemanfaatan sumberdaya laut untuk kepentingan pariwisata yang berkelanjutan. Perkembangan pariwisata di satu sisi akan menyebabkan semakin banyaknya sumberdaya yang digunakan untuk mendukungnya, sehingga upaya pengelolaan dengan penghematan dan konservasi seiring 
dengan pelaksanaan pariwisata menjadi sangat penting agar kelestarian sumberdaya dapat terus dapat lestari.

\section{Ekowisata sebagai Bentuk Pemanfaatan Sumberdaya Berkelanjutan}

Ketersediaan sumberdaya alam menjadi salah satu faktor penting dalam pembangunan suatu wilayah, di samping faktor sumberdaya manusia dan teknologi (Nugroho dan Dahuri, 2012; Muta'ali, 2013). Sektor yang sangat terkait secara langsung dengan sumberdaya alam yang ada di suatu wilayah adalah pertanian, perikanan, kehutanan, perkebunan dan pariwisata, khususnya wisata dengan objek alam.

Salah satu bentuk wisata adalah ekowisata. Ekowisata sendiri seringkali dijadikan lawan kata untuk wisata masal yang cenderung merusak. Meskipun demikian, pada prakteknya pemanfaatan sumberdaya alam untuk pariwisata biasanya diawali dengan wisata masal. Kemudian setelah nampak banyak kerusakan, kesadaran kemudian muncul untuk tidak sekedar mencari keuntungan, tetapi juga menjaga kelestarian lingkungan sebagai asset utama pariwisata.

Ekowisata diartikan sebagai kegiatan wisata yang menaruh perhatian besar terhadap kelestarian sumberdaya pariwisata (Damanik dan Weber, 2006). The International Ecotourism Society/ TIES (2000) menyebutkan bahwa ekowisata adalah perjalanan wisata alam yang bertanggung jawab dengan cara mengonservasi lingkungan dan meningkatkan kesejahteraan masyarakat. Berdasarkan dua pengertian di atas, setidaknya terdapat dua pokok tujuan ekowisata, yakni konservasi sumberdaya alam/pariwisata dan peningkatan kesejahteraan masyarakat. Tentunya hal ini akan sangat baik jika disesuaikan juga dengan target SDGs yang mengutamakan pada pengembangan budaya dan potensi lokal suatu wulayah.

\section{Goa Pindul sebagai Objek Wisata Strategis Daerah}

Goa Pindul secara administratif masuk di Desa Bejiharjo, Kecamatan Karangmojo, Kabupaten Gunungkidul, Daerah Istimewa Yogyakarta. Seacara geomorfologi wilayah ini menjadi anomaly di wilayah Basin Wonosari, sedangkang Geologi wilayah ini tersusun oleh batuan gamping yang masuk dalam Formasi Wonosari. Morfologi yang terbentuk adalah bukit-bukit karst dengan tipe kegelkarst yang telah mengalami perkembangan yang intensif dan telah didominasi oleh sistem pelorongan berupa sungai-sungai bawah tanah.

Kawasan Wisata Goa Pindul mampu menjadi salah satu obyek wisata unggulan di Kabupaten Gunungkidul dengan masukan Pemasukan 
Asli Daerah (PAD) sebesar Rp. 3.672.690.000,00 (Musadad, 2014) dari total PAD sektor pariwisata Kabupaten Gunungkidul sebesar Rp 6.100.000.000,00 (Sudarmadji, dkk, 2012). Peningkatan signifikan jumlah wisatawan terjadi pada peiode tahun 2012-2013, di mana jumlah kunjungan wisatawan naik dari kisaran 60.203 orang menjadi 122.423 orang (Musadad, 2014).

Kawasan Wisata Goa Pindul menawarkan berbagai atraksi wisata yang menarik ditinjau dari keunikan yang dimiliki oleh bentangalam karst. Keunikan bentangalam karst dapat terlihat dengan terbentuknya pelorongan goa dan sistem sungai bawah tanah (SBT) seperti yang ada di Kawasan Wisata Goa Pindul. Bentukan unik di bentangalam karst disebabkan karena adanya pelarutan batuan karbonat sehingga membentuk porositas sekunder yang dapat berkembang menjadi sistem sungai bawah tanah (Ford and Williams, 2007). Sistem sungai bawah tanah yang berkembang di Goa Pindul inilah yang dimanfaatkan oleh masyarakat sekitar menjadi atraksi wisata. Beberapa atraksi wisata yang ditawarkan di Kawasan Wisata Goa Pindul seperti cave tubing atau penyusuran aliran sungai bawah tanah yang masuk ke dalam goa dan kembali ke luar goa di sisi yang lain seperti yang disajikan pada Gambar 2 disertai dengan wisata seni budaya dan pendidikan berupa pengenalan kawasan karst dan segala fenomena yang terjadi di dalamnya.

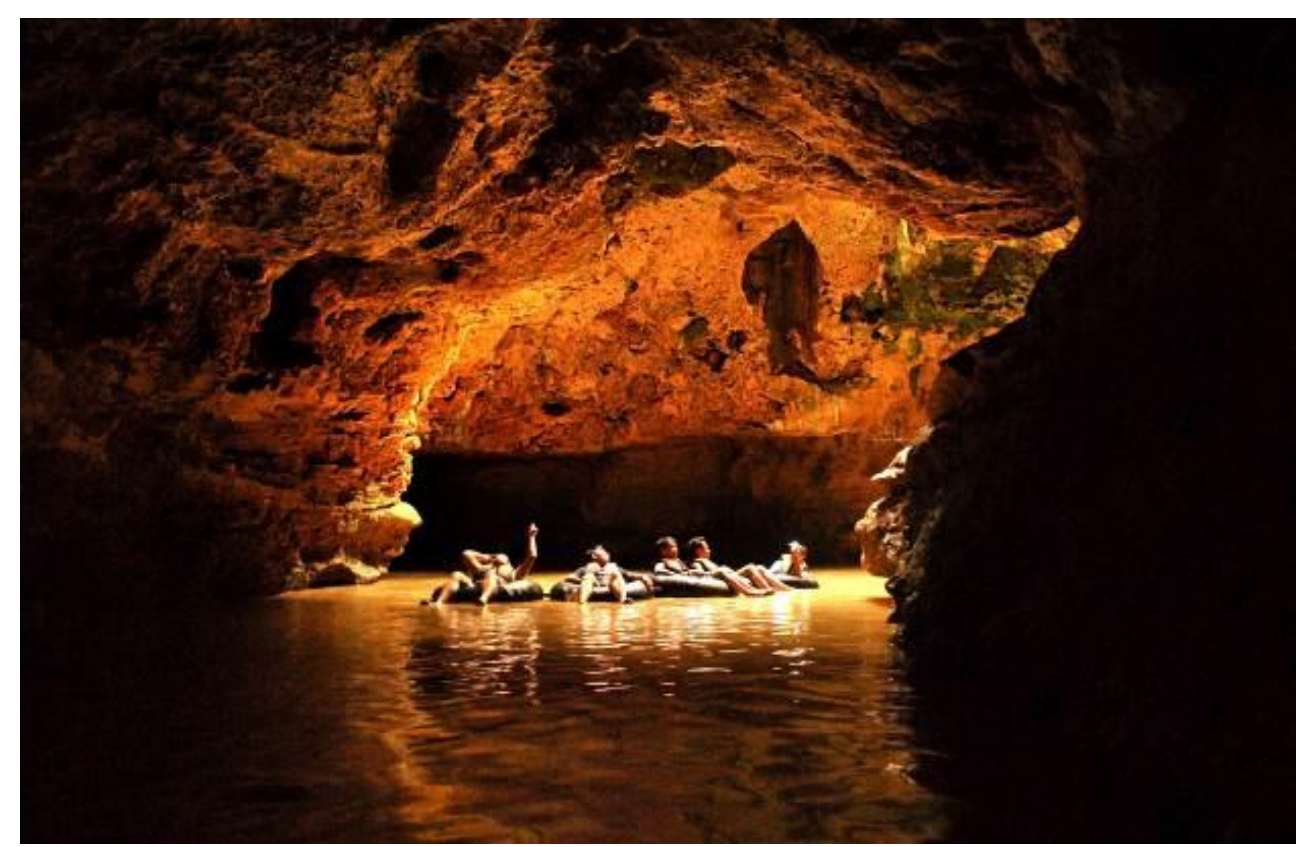

Gambar 2. Kegiatan Cave Tubing di Goa Pindul 


\section{Urgensi Pengelolaan Goa Pindul}

Selain memiliki potensi daya Tarik wisata yang tinggi, Goa Pindul juga memiliki potensi bencana yang harus diwaspadai. Sudarmadji, dkk (2012) menyebutkan bahwa Goa Pindul yang merupakan sungai bawah tanah memiliki input dari sungai permukaan. Kondisi wilayah tangkapan sungai permukaan yang luas dengan penggunaan lahan yang didominasi oleh tegalan dan permukaan tanah yang didominasi oleh lempung berat menyebabkan koefisien run off akan tinggi. Hal ini akan menyebabkan respon daerah tangkapan terhadap hujan menjadi kurang baik dan menghasilkan debit banjir yang besar. Oleh karena itu, maka diperlukan upaya-upaya mitigasi bencana banjir di wilayah Goa Pindul.

Goa sebagai sebuah bentukan alam yang rapuh terhadap perubahan sebenarnya memiliki daya dukung tersendiri. Pemanfaatan Goa Pindul untuk wisata masal selama ini memang telah menyebabkan kerusakan ekosistem di dalam goa. Selain rusak, kenyamanan pengunjung seringkali tidak lagi diperhatikan. Hal ini nampak dari banyaknya pengunjung selama musim liburan. Sampai saat ini, perhitungan daya dukung belum pernah dilakukan, sehingga tidak ada dasar penentuan jumlah wisatawan yang boleh masuk pada waktu tertentu.

Goa pindul sebagai objek wisata tentunya akan memberikan dampak domino seperti bergeraknya sektor yang lain seperti perdagangan, industri pertanian yang mengolah produk lokal serta jasa pendukung pariwisata. Besarnya uang yang berputar dalam kegiatan ekonomi di Goa Pindul juga menyebabkan rawannya terjadinya konflik sosial karena menimbulkan ketimpangan kondisi ekonomi antara wilayah di sekitar Goa Pindul dengan wilayah di sekitarnya. Hal ini kemudian memicu munculnya banyak sekretariat yang dikelola secara terpisah dari beberapa kelompok masyarakat dengan objek wisata yang sama. Persaingan yang tidak sehat juga nampak dari adanya calo yang berkedok pemandu wisata yang mengantarkan wisatawan ke lokasi sekretariat wisata tertentu. Hal ini juga nampak dari banyaknya calo yang kemudian menyesatkan wisatawan dengan memasang papan penunjuk arah yang tidak sesuai sehingga wisatawan terpaksa meminta tolong diantarkan ke lokasi wisata Goa Pindul.

Kondisi seperti di atas hendaknya segera di atasi oleh pemerintah daerah sebagai pihak yang berwenang di era otonomi daerah ini. Selain itu, konflik yang berlarut-larut hendaknya segera diselesaikan agar dampaknya tidak semakin besar. Batasan wisatawan, jumlah sekretariat, larangan penggunaan calo perlu segera direalisasikan.

Permasalahan lain yang penting diperhatikan adalah pengelolaah limbah dari kegiatan pariwisata. Jumlah wisatawan yang banyak tentu 
membutuhkan sistem pengelolaan limbah cair ataupun limbah padat. Kawasan karst yang rawan lagi mudah mengalami pencemaran membutuhkan dukungan teknologi yang baik agar tidak mengalami pencemaran dan kerusakan.

Sebagai kawasan karst yang relatif berkembang, Goa Pindul harus dikelola dengan sangat hati-hati. Pelorongan-pelorongan akibat proses pelarutan yang intensif pada batuan gamping akan menyebabkan karakteristik hidrologi yang unik (Cahyadi, 2010; Cahyadi dkk., 2013; Cahyadi, 2014). Masukan sungai Allogenik juga mengharuskan pengelolaan wisata di dalam goa harus mempertimbangkan terjadinya bencana banjir (Bahtiar dan Cahyadi, 2014). Wilayah tangkapan yang luas dengan tanah vertisol dengan material lempung akan menyebabkan hujan yang jatuh banyak yang menjadi aliran permukaan (Suprayogi dkk., 2016). Oleh karenanya selain pemantauan yang rutin harus dilakukan, perlu juga dilakukan analisis karakteristik banjir (hidrograf) dan inisiasi early warning system dan emergency response system sebagai bagian dari pengurangan risiko bencana banjir (Sudarmadji dkk., 2014; Sudarmadji dkk., 2015; Suprayogi dkk., 2015) di Kawasan Wisata Goa Pindul.

\section{Penutup}

Diperlukan kersama banyak pihak baik dari pemerintah, masyarakat, pelaku wisata dan peneliti agar pengelolaan Goa Pindul dapat dilaksanakan dengan pokok-pokok ekowisata. Wisata masal yang selama ini berlangsung semestinya tidak lagi dilanjutkan mengingat kawasan karst adalah kawasan yang sangat rawan mengalami kerusakan. Perencanaan pariwisata yang berkelanjutan dan memperhatikan aspek mitigasi bencana dan kelestarian lingkungan harus menjadi prioritas untuk segera diselesaikan.

\section{Pengakuan}

Makalah ini merupakan bagian dari hibah Penelitian Unggulan Perguruan Tinggi (PUPT) Kementerian Riset, Teknologi dan Pendidikan Tinggi (Kemenristekdikti) tahun 2016 yang berjudul "Karakterisasi Hidrologi dan Banjir di Sungai Bawah Tanah Goa Pindul untuk Pengelolaan Pariwisata Berkelanjutan Berbasis Manajemen Kebencanaan" dengan nomor kontrak 679/UN1-P.II/LT/DIT-LIT/2016.

\section{Daftar Pustaka}

Bahtiar, I.Y. dan Cahyadi, A. 2014. Analisis Karakteristik Hidrologi Aliran Sungai Bawah Tanah di Kawasan Karst untuk Mendukung Pengembangan Geowisata. dalam Cahyadi, A.; Prabawa, B.A.; 
Tivianton, T.A. dan Nugraha, H. 2014. Ekologi Lingkungan Kawasan Karst Indonesia: Mejaga Asa Kelestarian Kawasan Karst Indonesia, Edisi 2. Yogyakarta: Deepublish. Hal: 13-22.

Cahyadi, A. 2010. Pengelolaan Kawasan Karst dan Peranannya dalam Siklus Karbon di Indonesia. Prosiding Seminar Nasional Perubahan Iklim. Yogyakarta: Sekolah Pascasarjana Universitas Gadjah Mada.

Cahyadi, A.; Pratiwi. E.S. dan Fatchurohman, H. 2013. Metode-metode Identifikasi Karakteristik Daerah Tangkapan Air Sungai Bawah Tanah dan Mata Air Kawasan Karst: Suatu Tinjauan. dalam Marfai, M.A. dan Widyastuti, M. 2013. Pengelolaan Lingkungan Zamrud Khatulistiwa. Yogyakarta: Pintal. Hal: $50-61$.

Cahyadi, A. 2014. Keunikan Hidrologi Kawasan Karst: Suatu Tinjauan. dalam Cahyadi, A.; Prabawa, B.A.; Tivianton, T.A. dan Nugraha, H. 2014. Ekologi Lingkungan Kawasan Karst Indonesia: Mejaga Asa Kelestarian Kawasan Karst Indonesia, Edisi 2. Yogyakarta: Deepublish. Hal: $1-13$.

Damanik, J. dan Weber, H.F. 2006. Perencanaan Ekowisata: dari Teori ke Aplikasi. Yogyakarta: Penerbit Andi.

Ford, D.C. dan P.W. William. 2007. Karst Geomorphology and Hydrology. Chicester : John Willey and Sons.

Musadad. 2014. Partisipasi Masyarakat Dusun Gelaran II dalam Pengembangan Wisata di Goa Pindul, Kabupaten Gunungkidul. Thesis. Yogyakarta : Sekolah Pascasarjana UGM.

Muta'ali, L. 2011. Kapita Selekta Pengembangan Wilayah. Yogyakarta: Badan Penerbit Fakultas Geografi (BPFG) Universitas Gadjah Mada.

Muta'ali, L. 2013. Penataan Ruang Wilayah dan Kota: Tinjauan Normatif-

Teknis. Yogyakarta: Badan Penerbit Fakultas Geografi (BPFG) Universitas Gadjah Mada.

Nugroho, I. dan Dahuri, R. 2012. Pembangunan Wilayah: Perspektif Ekonomi, Sosial dan Lingkungan. Jakarta: LP3ES.

Sudarmadji; Suprayogi, S. dan Setiadi. 2012. Konservasi Mata Air Berbasis Masyarakat di Kabupaten Gunungkidul untuk Mengantisipasi Dampak Perubahan Iklim. Yogyakarta: Penerbit Sekolah Pascasarjana Universitas Gadjah Mada.

Sudarmadji; Marfai, M.A.; Cahyadi, A. dan Tivianton, T.A. 2014. Mitigasi Bencana di Lokasi Wisata Minat Khusus Kalisuci Gunungkidul. Prosiding Pekan IImiah Tahunan Ikatan Geograf Indonesia XVII. Yogyakarta: Universitas Negeri Yogyakarta. 
Sudarmadji; Marfai, M.A.; Cahyadi, A. dan Tivianton, T.A. 2015. Inisiasi Emergency Responese System di Lokasi Wisata Minat Khusus Kalisuci, Gunungkidul. Jurnal Geografi, 13(1):14-25.

Suprayogi, S.; Cahyadi, A. dan Tivianton, T.A.; Prabawa, B.A. 2015. Peningkatan Kapasitas Masyarakat dalam Manajemen Bencana Banjir Bandang di Lokasi Wisata Minat Khusus Kalisuci, Gunungkidul. Prosiding Seminar Nasional Kemandirian Daerah Dalam Mitigasi Bencana Munuju Pembangunan Berkelanjutan. Surakarta: Universitas Sebelas Maret.

Suprayogi, S.; Purnama, S.; Agniy, R.F. dan Cahyadi, A. 2016. Potensi Airtanah Statis di Daerah Tangkapan Air Goa Pindul, Kabupaten Gunungkidul. Prosiding Seminar Nasional Geografi Lingkungan I. Yogyakarta: Badan Penerbit Fakultas Geografi Universitas Gadjah Mada.

The International Ecotourism Society (TIES). 2000. Ecotourism Statistical Fact Sheet. TIES.

United Nation World Tourism Organization (UNWTO). 2016. UNWTO Annual Report 2015. Madrid: UNWTO.

Makalah ini merupakan bagian dari Buku Seri Bunga Rampai dengan Judul "Hidrologi dan Kepariwisataan Kawasan karst Goa Pindul Kabupaten Gunungkidul" dengan Editor Slamet Suprayogi, Setyawan Purnama, Ahmad Cahyadi, Hendy Fatchurohman. Buku ini diterbitkan oleh Badan Penerbit Fakultas Geografi (BPFG) Universitas Gadjah Mada di Yogyakarta Tahun 2016. Makalah ini termuat dalam Halaman 1 - 9 . 